\title{
Virtual Communities and their Importance for Informal Learning
}

\author{
Antonios Andreatos
}

\begin{abstract}
This paper deals with the concept of informal learning in virtual communities on the Internet. Initially we discuss the need for continuing education and its relation with informal learning. Virtual communities are next defined and then compared to real communities. Case studies are employed, focused on some specific kinds of virtual communities. We examine how they operate, how their members interact, what values they share and what kind of knowledge they gather. The learning process within virtual communities is then examined. We look at the kind of information and knowledge available in some particular virtual communities, and comment on its organisation. Next, the learning process of virtual communities is compared to that of Open Universities. Finally, we claim that the participation in virtual communities is not only a form of continuing education but also a contribution towards the multiliteracies needed for working as well as living in the 21 st century.

Keywords: Virtual Communities, informal learning, multiliteracies.
\end{abstract}

\section{Introduction}

\subsection{Defining informal learning}

Learning is a natural, spontaneous and lifelong process of human nature. Education, on the other hand, is a formal, structured, organised process with specific goals. The terms 'learning' and 'education' are often confused, because education is based on the learning process [1]. Learning may be formal, non-formal or informal [2].

1. Formal learning (what we usually call Education) is offered by elementary schools, high schools, colleges and universities; it is based on the teacher-student model.

2. Non-formal learning is still organised learning but outside the formal learning system; it is offered by official organisations such as governmental services, youth organisations, training services, scientific unions, enterprises, voluntary and non-profit organisations, etc.

3. Informal learning on the other hand is not organised nor organized but casual; even travelling or watching TV may lead to informal learning [1]. It is what we learn from everyday life [2].

\subsection{Continuing education and informal learning}

Social changes and the evolution of human knowledge in the Digital Era are so fast, that make further education imperative for many professionals. Like regular education, continuing education may be formal, non-formal or informal.

In a recent research among the engineers - members of the Technical Chamber of Greece, it was found out that [3]:

- The great majority $(92,5 \%)$ believes that continuing professional education is necessary for finding a (good) job. A percentage of 50,6 \% believes that this education should take place every 3 years, while another $22 \%$ places this time to every 5 years.

- A majority of 56,4\% believes that the most important needs for continuing professional education are related to computers and new technologies. 
- A percentage of $49 \%$ has attended (or attends currently) a professional continuing education program, while most of those who have not attended such a program $(60,1 \%)$ declare as the most important reason the lack of time due to work overload.

From the above we conclude that professional continuing education program is necessary for many professionals. According to the Institute for Research on Learning, located in Menlo park (2000), at least $80 \%$ of the professional knowledge, skills and practices needed for many jobs is informal [4]. Since a lot of professionals lack the time needed for attending a non-formal professional continuing education program, they have to learn new things and acquire new skills informally. Since informal education is so important, it is worth to be further examined.

The most important characteristics of informal learning are [1], [4]:

- It does not take place in special educational establishments standing out from normal life and professional practice;

- It has no curriculum and is not professionally organized; it rather stems accidentally, sporadically, in association with certain occasions, from the changing practical requirements;

- It is not planned pedagogically, nor systematically organised in subjects;

- It is not qualification-oriented, nor officially recognised;

- It is not formally organised and financed by institutions;

- It is rather practical than theoretical;

- It is rather unconscious, incidental problem-related and therefore, well-focused;

- It is not instructed by a teacher or a course designer but rather self-directed;

- It is closely related to professional practice;

- It is a tool for living and survival.

The ability of informal continuous self-education and training is a vital skill for today's professionals. Knowledge is outdated fast, so a professional has to continually update his/her experiences and knowledge profile, if they want to be competitive.

In this paper we are interested in studying informal learning, in relation to Virtual Communities (VCs). It is a process which lies between the non-formal education, defined above, and casual learning. The actual point varies from person to person [5]. It is not casual learning, because it aims at a goal; and the goal has to do with the common interest of the VC members. A user participates in a VC which deals with his/her interest(s), either for professional reasons or as a hobby.

\section{Defining virtual communities}

\subsection{The era of new media}

The Internet has dramatically changed the way people get informed, interact and communicate in the 21 st century. Distribution of information and knowledge is nowadays carried out more and more via the Internet [5]. It is characteristic that new terms such as blogs, bots, wikies and podcasting [6], [7] were unknown some years ago, and are still not registered in most (paper) dictionaries. Here lies the Internet advantage: it is the only medium that instantaneously follows today's social evolutions. Not only that, but it is actually driving the evolution. In 1988 there were about 30.000 blogs available; today, there are more 
than 35 million [8] and it is estimated that every second a new blog is created (www.technorati.com). On the other hand, Philip Meyer, author of the book "Vanishing newspaper: saving journalism in the Information Age", estimates that, with current trends, the last newspaper reader will recycle that last newspaper in April 2040 [8]! Some types of new media, along with representative examples, are given below [9]:

- BBS: The WELL, GEnie

- Blog: LiveJournal, Xanga, MySpace, Facebook, Blogspot, Blogger, Myciab

- Webcomic: UserFriendly, Penny Arcade, Sluggy Freelance

- Habitat: LucasFilm's Habitat, VZones

- IM: ICQ, Yahoo! Messenger, MSN Messenger, AIM

- IRC/EFNet

- MMORPG: Everquest, Ultima Online, World of Warcraft, Silk Road Online

- MOO: LambdaMOO

- MUD/MUSH: TinyMUD

- P2P: Napster, KaZaA, Gnutella, Morpheus

- USENET

- Wiki: Wikipedia, WikiWikiWeb, PBWiki, Wetpaint

- WWW: eBay, GeoCities, Slashdot.

\subsection{Towards a definition}

The birth of Virtual Communities is placed at the early years of the Arpanet, back to the seventies; the World Wide Web was not invented yet. Today they are well-established forums, i.e. virtual places for communicating and exchanging information. However, the term virtual community appeared in 1993 and it is attributed to the homonymous book by Howard Rheingold [10]. The book discusses a variety of Information and Communication Technology (ICT) -based communication and social groups. The technologies included Usenet, Internet Relay Chat (IRC), chat rooms, electronic mailing lists and gaming communities such as Multi-User Dungeon (MUD) and its clones (e.g., MUSH and MOO). Rheingold pointed out that belonging to such a group has some potential benefits for the personal psychological health, as well as for the society in general [9]. According to Rheingold, virtual communities are formed "when people carry on public discussions long enough, with sufficient human feeling, to form webs of personal relationships" [10].

The explosive diffusion of the Internet in certain countries was also accompanied by the proliferation of virtual communities. The nature of those communities and communications is rather diverse [9].

Today, virtual communities or online communities are used by a variety of social groups interacting via the Internet. Different virtual communities, like real communities, have different levels of interaction and participation among their members. An important characteristic of a community is the interaction among its members. Thus, an email distribution list with hundreds of recipients with zero or low interaction among members, may not be called a virtual community. Similarly, placing comments or tags to a blog or message board may not constitute a community. The highest degree of interaction is achieved in video gaming communities, where users compete online against other users. Like traditional social 
groups or clubs, virtual communities often divide themselves into cliques or even separate to form new communities. Also, membership turnover rate varies greatly from VC to VC [9]. Each community shares its own interests, values, jargon [6], titles, leaders, ways of communicating and exchanging information and knowledge.

\subsection{Comparison of VCs to real communities}

There is of course no substitute to interpersonal communication, but it may be limited by distance. On the other hand, in VCs the distance factor is not applicable. The ability to interact with likeminded individuals instantaneously from anywhere on the globe has considerable benefits. Perhaps the greatest advantage is that the common interests are guaranteed in VCs, whereas this is not the case in real companies based on proximity.

The use of multimedia technologies greatly facilitates long-distance communication today. Evolution of technology will eventually bring multimedia (image, video etc) dimensions in digital communication, a fact which will enrich it further. Of course, the participation in a $\mathrm{VC}$ presupposes some familiarisation with ICT and the relevant equipment (PC, Internet connection etc).

In real-life friendships, age is often a critical factor. Usually, one's friends are around the same age. Generation gap constitutes a strong unwritten law in many societies. Yet, in virtual communities there is no age barrier. This is very important in many countries -including Greece- where the majority of Internet users are young people and higher age groups are minorities [11].

Since the personal characteristics of live communication are absent in VCs, user personalities are denoted by other symbols like nickname, personal information (such as email, website, blog, IRC number, Skype usernames etc), image/ personal mark/ signature, equipment related to the community interests (e.g. car, PC, cameras etc), user's achievements related to the community interests etc. VCs should be seen as supplementary to the real communities and not as alternatives or substitutes.

\section{Case studies}

The examination of some case studies will further clarify the above discussion.

1. Scientific union of Adult Education (of Greece, www.adulteduc.gr). The common interest here is professional. The Union organises conferences, seminars and meetings all around Greece; it also issues an online bimonthly bulletin for briefing and member communication. This also contains information on newly-edited books and scientific journals and the corresponding links on adult learning, information on instructor certification etc. A similar example is 'the Hellenic Network of Open and Distance Education' (www.opennet.gr). These communities have a professional character, are a bit more formal (e.g., no nicknames), have a hierarchy (president and members). They have a continuing education as well as a self- education character.

2. Hellenic Linux club (www.hellug.gr). This club is a Greek official and non-profit association of people working with or using or positively predisposed to Linux. Its aim is the union of such individuals, the communication among them in order to tighten their privities, as well as, the further proliferation of this operating system. Means for achieving the above goals are: meetings, problem solving support, translation of documents and articles in Greek; improvement of Greek language support in Linux; development of free software; presence in meetings, conferences and exhibitions; collaboration with peer clubs with common goals; diffusion of know-how; Follow-up and intervention whenever the interests of Linux are threatened.

A similar site is: www.linux.gr. It contains news, documentation, articles, download material, links, Guidelines for various Linux distributions, guidelines for beginners, indexing and an electronic magazine. Linux blogs (for instance: http://linuxhelp.blogspot.com, 
http://www.computerworld.com/blogs/software/os/linux, http://linux-blogger.com, and http://www.suseblog.com) are also available.

3. www.overclockers.com: perhaps what is more admired here is the extra $\mathrm{MHz}$ a user can get out of his new PC, or, the exotic water cooler system one has constructed.

VCs such as the second and the third one listed above, may be characterised as hobbyist or amateur communities rather than professional. Such VCs are more free, more non-formal, more casual. They share different values than the formal ones. Nicknames are used instead of real names. A couple of examples (with pseudonyms) are: "John Smith - aka Shroomer in the Forums", "My name is Valentino Jones, a.k.a Cr@zyVJ on the net, and friends simply call me VJ". Also, former education titles are not so important; the most important virtues are: expertise, participation and voluntarism to help other users.

\section{Learning in Virtual Communities}

\subsection{Organisation of knowledge in VCs}

In a formal distance learning environment the educational material is well organised: (i) the courses are structured in a prerequisite order, from the fundamental to the most complicated. (ii) The educational material is composed of Learning Objects (LOs) [2]. Many LOs form a course and many courses form a curriculum. Among the various courses there is no (or minimal) overlap. (iii) The educational material is usually managed by a Learning Management System (LMS) [2], [13].

Let us assume that the information / knowledge resources of a VC are the contents of its node (such as website or a blog). In this case, the material is rather chaotically organised, with high overlaps, no particular structure, no particular management. Homepages link to several sub-pages and other related nodes. The various similar VC nodes (e.g., Linux communities) are loosely connected. The ability to find specific information requires sometimes specific skills of searching and data mining. However, there is still a hidden hierarchy: the first level is the knowledge present in the node, which may be downloaded; the second level is the knowledge and experience of the community members, which is not seen.

\subsection{Looking for information in VCs}

The most common ways for getting access to specific information from VCs are:

1. Download articles from their nodes

2. Participate in fora and pose questions

3. Read FAQs and search for keywords

4. Use the site search engine (if available)

5. Contact sage membres ('gurus', 'masters' etc.) directly.

However, since the material is not organised, a user may have to search for several minutes in order to find what he/she is looking for.

\subsection{Comparison to Open University practices}

There exist strong similarities but also differences between the ways learning is achieved on line in virtual communities and Open Universities (OU) using the Web. As an example of an Open University we shall consider the Hellenic Open University (HOU) [www.eap.gr]. HOU students interact with their 
instructor as well as with each other over the Internet frequently, in order to ask questions and get answers about the educational material and particularly the assignments they have to carry out. Mostly the interaction is done by emails and forums. The students are all provided with the same books and are supposed to follow a specific syllabus. The students meet regularly five times throughout the course of a year; attendance is not required. In the end of the academic year they also take an exam (live) which is mandatory and counts for $70 \%$ of the final grade. All these practices do not occur in VCs, where learning is informal. But there is a strong similarity in that the students study and learn on their own. This practice is fundamental for the institution and operation of all OUs worldwide [3]. Similarities between OUs and VCs are listed in Table 1 below. Table 2 lists some differences.

\begin{tabular}{|l|}
\hline Students / members study on their own \\
\hline They depend a lot on the educational material \\
\hline They help each other gain specific knowledge or skills \\
\hline They may be assessed by knowledge or skills (titles or grades or expertise) \\
\hline They may be anywhere in the world \\
\hline They are adults and therefore, self-motivated \\
\hline They are moderated by an instructor or a list moderator or owner of the site \\
\hline
\end{tabular}

Table 1: Similarities between OUs and VCs

\begin{tabular}{|l|l|}
\hline Open Universities & Virtual Communities \\
\hline Students are directed by the instructors & Members of VCs are self-directed \\
\hline $\begin{array}{l}\text { Students are provided with the same educa- } \\
\text { tion material }\end{array}$ & $\begin{array}{l}\text { Members study different material and prac- } \\
\text { tice a lot }\end{array}$ \\
\hline $\begin{array}{l}\text { Students are supposed to follow a specific sy- } \\
\text { llabus }\end{array}$ & There is no syllabus \\
\hline Students have seen each other at least once & Real life interaction may never take place \\
\hline Focus primarily on knowledge & Focus primarily on expertise \\
\hline Provide a title & Do not provide a title \\
\hline Knowledge is more theoretical & Knowledge is more practical and empirical \\
\hline
\end{tabular}

Table 2: Differences between OUs and VCs

\subsection{Professionals and continuing education}

Today the Internet is used by millions of people as an interminable pool of knowledge, as a huge online encyclopaedia. A user seeking particular information on a subject, may find a lot of it, not only in online encyclopaedias or dictionaries but also in specialised VC nodes. For this reason, the ability of informal self-education and training is a vital skill for today's professionals. Based on personal experience, we believe that information and knowledge gathered in some specific VC-related nodes, is superior to that available in traditional, even academic, sources such as books, electronic or conventional, in terms of practicality and in-depth and up-to-date coverage. Since VCs update continually the (practical) skills of their members, we can claim that they offer some kind of informal education [15].

The user groups of these professional sites may be regarded as loose professional communities with no or limited interaction amongst users. Many profit and non-profit organisations offer (often for free) seminars via the Web (also knows as 'Webinars') to their customers or community members. The main purpose of most such webinars is to demonstrate the use of the companies' products (such as software tools, integrated circuits, e-Learning platforms, etc.). Let's look at some examples. 
The MathWorks Inc. offers free, live and interactive monthly webinars concerning the use of MATLAB toolboxes. SABA, an e-Learning systems company, also offers live online webinars (www.saba.com). National Semiconductor (www.national.com) offers online seminars for design engineers. Microsoft maintains a large 'knowledge base' with articles for computer and network professionals.

Teacher unions and communities do not lag behind. Let us examine two case studies from the Greek national Internet domain:

- 'EEEP', the Greek Primary Teachers Association for the valorisation of ICT in education, a nonprofit open community. They issue a journal, organize conferences and maintain a vivacious site (eeep.gr). Users can read news and download their electronic magazine (sometimes called a 'webzine').

- The aforementioned Scientific union of Adult Education (of Greece) [www.adulteduc.gr] is another example. They organise conferences, seminars and meetings all around Greece; it also issues an online bimonthly bulletin for briefing and member communication.

\subsection{VCs and 'multiliteracies'}

In a pioneer as well as important article published in 1996, the 'New London Group' argues that today's world is characterised by an increasing cultural and linguistic diversity and a variety of new communication ways and channels, due to the evolution of ICT. According to the authors, traditional language-based pedagogical approaches do not provide adequate skills for working and living in general in today's multi-cultural societies, and that, a new approach to literacy pedagogy, which they have called 'multiliteracies', is needed instead. Multiliteracies are based on the assumption that the multiple linguistic and cultural differences in our society is essential to the working and private lives of students. The use of multiliteracies approaches to pedagogy will enable students to achieve the following two goals: a) create access to the evolving language of work and community; and b) foster the critical engagement necessary for them to design their social futures and succeed through satisfying employment [16], [17].

\section{Discussion and conclusion}

In this paper we have examined Virtual Communities (VCs); more specifically, we have dealt with three types of VCs: video game VCs, professional VCs and amateur VCs. We have identified some differences among them, as well as, some similarities and differences between VCs and real-life communities. Next we have examined informal learning in VCs and we have compared the organisation of knowledge in VCs to that of distance learning courses. Learning gained by the participation in VCs was briefly compared to the methods followed by open universities. Furthermore, it was claimed that new 'digital' skills are needed by 21 st-century citizens.

From the discussion above we may conclude that for a professional, participation in professional VCs may be akin to continuing education, whereas for a non-professional, it may merely serve as entertainment. Of course, professionals may also benefit from non-professional VCs. In any case, however, free-will participation in VCs is very important, because it fosters the necessary 'digital behaviour' and cultivates 'digital communication' skills.

Based on personal experience, we believe that information and knowledge gathered in some communityrelated nodes concerning practical subjects, is superior to that available in traditional, even academic, sources such as books, electronic or conventional.

Nowadays, where a multiliteracy education is needed for living and working in the digital era, digital communication skills are necessary. 'Digital behaviour' and 'digital communication' rules and ethics are being developed; therefore, all contemporary people should be 'digitally literate', in order to be able to survive in a changing and competitive environment. Real communication skills are not enough; 'digital 
communication' skills are also needed. The ability to use the Internet and the new media is vital for surviving in the 21 st century.

VCs will continue to play an important role in 21st-century society, due to social evolution, the globalisation of economy and knowledge, competition and new media technologies.

\section{Acknowledgement}

Author wishes to thank Mr. M. Vidalis for reviewing the manuscript.

\section{References}

[1] A. Rogers, Teaching Adults, Open University Press. 1996.

[2] http://en.wikipedia.org/wiki/Learning, retrieved on Dec. 11, 2006.

[3] Continuous further education is necessary - Changes in syllabus are imperative, News bulletin of the Technical Chamber of Greece, no. 2423, Jan. 15, pp. 6-8. 2007.

[4] http://en.wikipedia.org/wiki/Informal_learning, retrieved on Dec. 11, 2006.

[5] A. Vardamaskou and P. Antoniou, Informal learning: evaluation of an Internet-based physical activity educational program for adults, Proceedings of the 3rd International Conference on Open and Distance Learning, Patra, Greece, vol. A, pp. 405-417 (in Greek), 2005.

[6] S. Ververidis, The glossary of New Media, Kathimerini (newspaper) special edition: New media: the alternative choice, 28, pp. 88-89 (in Greek). 2006.

[7] D. Doulgeridis, Electronic diaries in common view, Tachydromos magazine, no. 266, pp. $44-49$ (in Greek). (2005)

[8] C. Angelopoulos, Blogs change the landscape of communication, special edition of Kathimerini (newspaper): New media: the alternative choice, 28, pp. 78-79 (in Greek), 2006.

[9] http://en.wikipedia.org/wiki/Virtual_communities, retrieved on May 15, 2006.

[10] H. Rheingold, The Virtual Community: Homesteading on the Electronic Frontier, Harper Perennial, San Francisco, 1993; also available on line at : www.rheingold.com/vc/book, retrieved on May 29, 2006.

[11] VPRC National research for new technologies and Information Society, Available online at: http://www.vprc.gr/2/1232/21_gr.html, in Greek, 2005, retrieved on Sept. 29, 2006

[12] F. Pantano-Rokou, Educational design for e-learning: models, meaning and impact on learning, Open Education, 1, pp. 45-68 (in Greek), 2005.

[13] G. Dimauro et al., An LMS to support e-learning activities in the university environment, WSEAS Transactions on Advances in Engineering Education, vol. 3(5), pp. 367-374. 2006.

[14] D. Vergidis, A. Lionarakis, A. Lykourgiotis, B. Makrakis and Ch.Matralis, Open and distance learning, vol. 1, Institution and Operation, Hellenic Open University, Patra (in Greek; title of book translated by paper author), 1998. 
[15] A. Margetousaki and P. Michaelides, Communities of Practice as a place of learning and development, Proceedings of the 3rd Pan-Hellenic conference on the Didactics of Information Science, Corinth (in Greek), Oct. 2005.

[16] The New London Group, A pedagogy of multiliteracies: designing social futures, Harvard Educational Review, vol.66, no.1, pp. 60-92, 1996.

[17] J. Salpeter, 21st century skills: will our students be prepared?, Available online at: www.techlearning.com/story/showArticle.jhtml?articleID=15202090, 2003, retrieved on March 22, 2006.

Antonios Andreatos

Dept. of Aeronautical Sciences

Div. of Computer Engineering and Informatics

Hellenic Air Force Academy

Dekeleia, Attica, TGA-1010 GREECE

E-mail: andreatos@hafa.gr

Received: November 17, 2006

Editor's note about the author:

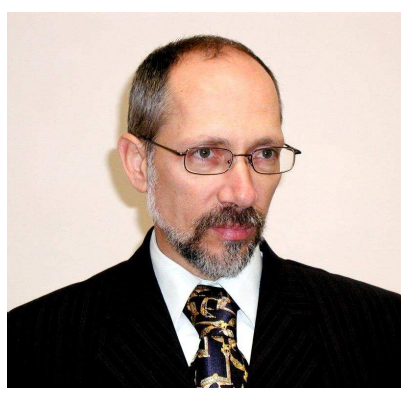

Antonios Andreatos is a Professor at the Computer Engineering Division of the Hellenic Air Force Academy. He was born in 1960 in Athens, Greece. He received the Diploma in Electrical Engineering from the University of Patras in 1983, the M.S. degree from the University of Massachusetts (Amherst) in 1985 and the Ph.D. from the National Technical University of Athens (NTUA) in 1989. He was a research scholar at the European Joint Research Centre of Ispra, Italy. He has published various papers in journals and conferences; he has also authored a book on the design of Microcomputer Systems in 2001. He has also taught at the Hellenic Open University. His main technical interests lie in the areas of microprocessors, computer architecture, computer networks, e-learning and adult education. 